\title{
TEC variations over the Mediterranean during the seismic activity period of the last quarter of 2005 in the area of Greece
}

\author{
M. E. Contadakis, D. N. Arabelos, G. Asteriadis, S. D. Spatalas, and C. Pikridas \\ Department of Geodesy and Surveying, Aristotle University of Thesaloniki, Greece \\ Received: 14 July 2008 - Revised: 30 September 2008 - Accepted: 30 September 2008 - Published: 25 November 2008
}

\begin{abstract}
In this paper the Total Electron Content (TEC) data of eight Global Positioning System (GPS) stations of the EUREF network (AUT1, Thessaloniki, TUC2, Crete in Greece, MATE, Matera, LAMP, Lampedusa in Italy, GAIA, in Portugal, RABT, Rabat, EVPA, Evpatoria in Ukrain and TRAB, Trabson in Turkey) were analysed using wavelet analysis in order to detect any frequency dependence of the correlation between TEC over different stations. In the same time frequency dependence of Dst (Global geomagnetic field disturbances) and TEC variations over each GPS station are searched in order to detect any correlation between them. The main conclusion of this analysis is that the components of TEC variation with periods $<3 \mathrm{~h}$ are more suitable in searching for earthquake precursors. On the base of this conclusion the analyzed TEC series are searched for possible precursory phenomena on the occasion of the seismic activity of the last quarter of 2005 in the area of Greece. An exalting (i.e. an increase in the amplitude) of variations with periods up to the tidal ones (period of $6 \mathrm{~h}, 8 \mathrm{~h}, 12 \mathrm{~h}$ ) may be observed a month before and during the seismic activity over the stations TUC2 and AUT1 and may be attributed to this tectonic activity. Statistical properties of the $1.5 \mathrm{~h}$ component of the Total Vertical Electron Content (TVEC) over the nearest GPS stations (TUC2 and AUT1) of the areas of the seismic activity indicate that this component present characteristic exalting in the time period of 15 days before the shock.
\end{abstract}

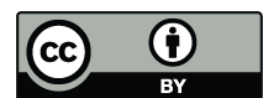

Correspondence to: M. Contadakis (kodadaki@vergina.eng.auth.gr)

\section{Introduction}

It is well known that TEC variations reveal ionospheric variations of different nature:

i) Global, like earth revolution, earth rotation, earth-tides, variations of the geomagnetic field, Solar activity etc. (Svets et al., 2004; Biagi et al., 2003; Crowley and McCrea, 1988; Afraimovich, 2000); ii) Local such as atmospheric or underground explosions, volcanoes, extreme weather phenomena (Calais et al., 1998; Jacobson and Carlos, 1988; Afraimovich et al., 2000); iii) Earthquakes (Afraimovich et al., 2001; Molchanov et al., 2004; Molchanov et al., 2005; Meister et al., 2002; Liperovsky et al., 2002; Shvets et al., 2004).

A lot of work has been done by a great number of researchers on the characteristics of ionospheric variations (wave-length, attenuation, velocity and way of propagation (Afraimovich et al., 2002)) according to their nature as well as on the theoretical explanation (Molchanov et al., 2004; Rapoport et al., 2004a, b; Koshevaya et al., 2005). Nevertheless in order that TEC variations over a particular site are used as earthquake precursory diagnostic a concrete sense of the interrelation of TEC variations over different sites as well as their respond to the geomagnetic field variations would be of great interest. In this paper the TEC data of eight widely remote from Thessaloniki GPS stations of the EUREF network (http://www.epncb.oma.be) (AUT1, Thessaloniki, TUC2, Crete in Greece, MATE, Matera and LAMP, Lampedusa in Italy, GAIA, in Portugal, RABT, Rabat, EVPA, Evpatoria in Ukrain and TRAB, Trabson in Turkey) were analyzed using wavelet analysis in order to detect any dependence of the correlation of TEC variations over these stations with the frequency. In the same time frequency dependence of Dst and TEC variations over each GPS station are searched in order to detect any correlation between them. Finally comparative analysis of TEC variation over the stations of the network has been performed in order to detect any unusual characteristic of TEC variation over the area of Greece, which can be related to the seismic activity.

Published by Copernicus Publications on behalf of the European Geosciences Union. 
Table 1. Coordinates of the selected stations.

\begin{tabular}{lccc}
\hline Station & Latitude & Longitude & Height $(\mathrm{m})$ \\
\hline GAIA & $+41^{\circ} 06^{\prime} 21.60^{\prime \prime}$ & $-08^{\circ} 35^{\prime} 20.40^{\prime \prime}$ & 287.8 \\
RABT & $+33^{\circ} 59^{\prime} 53.17^{\prime \prime}$ & $-06^{\circ} 51^{\prime} 15.44^{\prime \prime}$ & 90.1 \\
LAMP & $+35^{\circ} 29^{\prime} 58.92^{\prime \prime}$ & $+12^{\circ} 36^{\prime} 19.80^{\prime \prime}$ & 57.8 \\
MATE & $+40^{\circ} 38^{\prime} 56.76^{\prime \prime}$ & $+16^{\circ} 42^{\prime} 16.20^{\prime \prime}$ & 535.6 \\
AUT1 & $+40^{\circ} 34^{\prime} 00.54^{\prime \prime}$ & $+23^{\circ} 00^{\prime} 14.01^{\prime \prime}$ & 150.0 \\
TUC2 & $+35^{\circ} 31^{\prime} 59.48^{\prime \prime}$ & $+24^{\circ} 04^{\prime} 13.37^{\prime \prime}$ & 161.0 \\
EVPA & $+45^{\circ} 13^{\prime} 10.17^{\prime \prime}$ & $+33^{\circ} 09^{\prime} 1.70^{\prime \prime}$ & 39.4 \\
TRAB & $+40^{\circ} 59^{\prime} 40.92^{\prime \prime}$ & $+39^{\circ} 46^{\prime} 32.16^{\prime \prime}$ & 99.2 \\
\hline
\end{tabular}

\section{Data and analysis}

\subsection{TEC and Dst data}

The development of GPS and GLONASS satellite systems provide us a perfect opportunity for a simultaneous inspection of TEC variations over a great number of locations around the earth and furthermore to investigate any interrelation of these variations or isolate variations of TEC which may occur over a particular site. These variations may be attributed to local nature.

Since we are interesting for TEC variation over Greece for this preparatory stage, in which we investigate the general characteristics of TEC variations, the TEC data of eight widely spread over Mediterranean GPS stations of the EUREF network (http://www.epncb.oma.be) (GAIA, in Portugal, RABT, Rabat, EVPA, Evpatoria and TRAB, Trabson) were analyzed. Figure 1 displays the EUREF network while Table 1 displays the coordinates of the selected GPS stations. The sites of the selected GPS stations are shown in Fig. 2 with blue triangles.

The data consist of TVEC values sampled every $45 \mathrm{~min}$ for each station and for six months, from September 2005 to February 2006. For the analysis of the geomagnetic field we use Dst-index quoted from the site of the Space Magnetism Faculty of Science, Kyoto University (http://swdcwww.kugi. kyoto-u.ac.jp/index.html). A sample of the variations of geomagnetic field and the variations of TVEC over one of the selected GPS stations are displayed in the upper part of Fig. 4a.

\subsection{Seismic activity on Eastern Aegean}

During October of 2005 an extensive seismic activity occurred on Eastern Aegean (Papadopoulos et al., 2006). This activity consisted of a series of great number of shocks with magnitudes $3.0 \leq \mathrm{M} \leq 5.6$ which peaked at 20 October with an earthquake of magnitude 5.6 and epicenter $\phi=+38.15^{\circ}$ and $\lambda=+26.63^{\circ}$. Table 2 displays the outstanding earthquakes of this series (Papadopoulos et al., 2006).

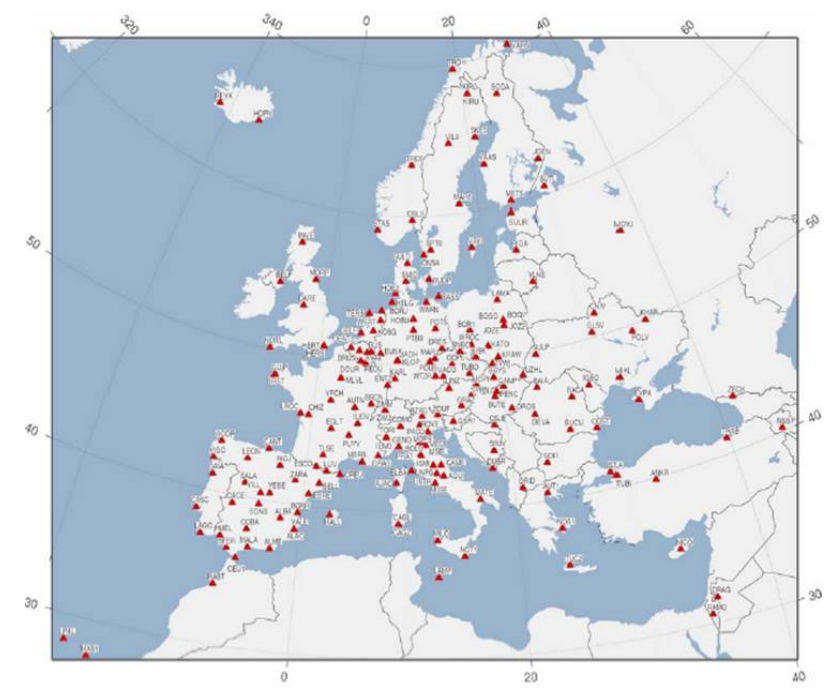

Fig. 1. GPS permanent stations of EUREF network.

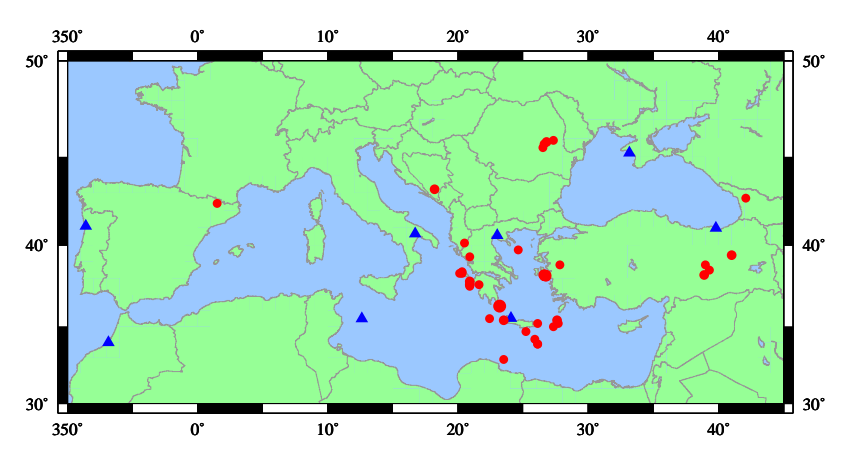

Fig. 2. Events with magnitude $>4.0$ around the Mediterranean which occurred in the last quarter of 2005(red cycles) and the selected GPS stations (blue triangles).

\subsection{Seismic activity in the area of Kythera (Southern Greece)}

On 8 January 2006 at 11:34 GMT, a strong earthquake with a moment magnitude of 6.7 and focal depth of $60 \mathrm{~km} \mathrm{oc-}$ curred near the eastern coast of the island Kythera of Southern Greece. Table 3 displays the characteristics of the preshocks, main shock and main aftershocks (Konstantinos et al., 2006).

\subsection{Seismic activity in the broader area}

During this period there exists an extending seismic activity with shocks up to the magnitude 5.0 mainly around the Greek arch. Table 4 displays the characteristics of these shocks quoted from the web site Orfeus Wilbert II, http: //www.orfeus-eu.org/cgi-bin/wilberII/wilberII_page2.pl and Fig. 2 displays the locus of the listed shocks in red cycles and the locus of the selected GPS stations in blue triangles. 

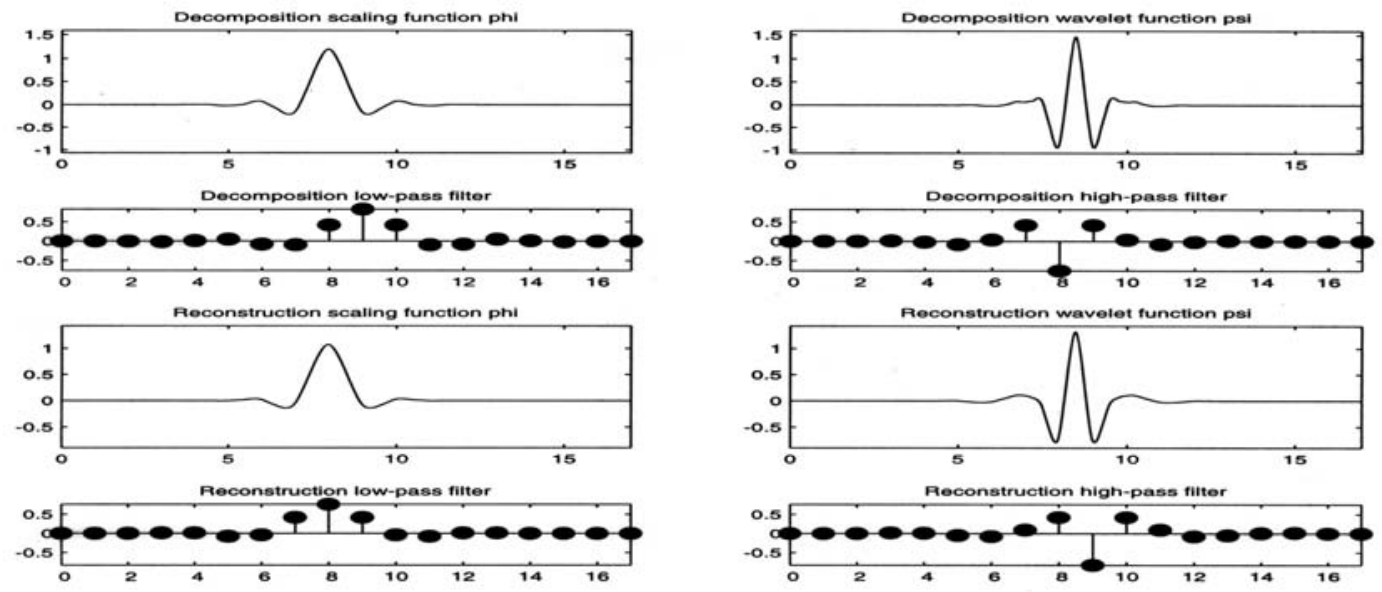

Fig. 3. Characteristic of wavelet Biorthogonal 6.8. Upper part: Decomposition: scaling function phi (left) and wavelet function psi (right), bellow them, the low- and high- pass filters respectively. Lower part: the same as for the reconstruction.

Table 2. The main earthquakes of the series.

\begin{tabular}{lcccc}
\hline Date/UT & Magnitude & Latitude & Longitude & Depth $(\mathrm{km})$ \\
\hline 17-10/05:45:18.3 & 5.5 & $+38.13^{\circ}$ & $+26.59^{\circ}$ & 29 \\
17-10/09:46:56.0 & 5.4 & $+38.14^{\circ}$ & $+26.59^{\circ}$ & 26 \\
20-10/21:40:03.5 & 5.6 & $+38.15^{\circ}$ & $+26.63^{\circ}$ & 25
\end{tabular}

\subsection{Correlation between Dst-variation and TVEC varia-} tions

A first attempt to find any correlation between TVEC variation in different sites as well as Dst and TVEC variation, reveal the expected correlation between TVEC over different sites and no correlation between Dst and TVEC as a result of the pronounced diurnal TVEC variation. As an example Table 5 displays the correlation coefficients for these quantities for September 2005.

A better insight into the possible correlation of the variations in TVEC and in Dst may be gained if we compare their frequency components. Wavelet analysis technique offers us an analysis of the variations of these quantities in the time-frequency domain and thus the ability to compare their frequency components.

For the wavelet analysis we use the wavelet Biorthogonal 6.8. This is a compactly supported wavelet for which symmetry and exact reconstruction are possible and can be used for Discrete as well as for Continues wavelet analysis. Figure 3 displays the characteristic of the wavelet Biorthogonal 6.8 (Misiti et al., 1996). We choose this wavelet because it is symmetric and sharp cutting something that intuitively we expect to properly suit for the analysis of TEC variation.

As an example Fig. 4 displays the Dst and TVEC variations for February 2006 over the GPS stations. Figure 4a displays the Dst variations in $\mathrm{nT}$ (upper part of the respective
Table 3. The main earthquakes of the series.

\begin{tabular}{lcccc}
\hline Date/GMT & Magnitude & Latitude & Longitude & Depth $(\mathrm{km})$ \\
\hline 07-01/05:10:41.6 & 5.0 & $+36.30^{\circ}$ & $+23.50^{\circ}$ & 30 \\
08-01/11:34:53.1 & 6.7 & $+36.21^{\circ}$ & $+23.41^{\circ}$ & 60 \\
11-01/10:34:00.0 & 4.3 & $+36.17^{\circ}$ & $+23.41^{\circ}$ & 45 \\
11-05/01:47:00.0 & 4.3 & $+36.19^{\circ}$ & $+23.48^{\circ}$ & 75 \\
\hline
\end{tabular}

quantity) as well as the coefficient plots (lower part of the respective quantity). The abscissa is the time elapsed from the beginning of the month (00:00 h U.T.) in multiple of $45 \mathrm{~min}$ and the ordinate is the period also in multiple of $45 \mathrm{~min}$.

From the coefficient plots we may see that the largest variations of the geomagnetic field correspond to smaller frequencies i.e. larger periods (periods $>24$ ordinate units $=16 \mathrm{~h}$ ) while smaller variations may correspond to the diurnal semidiurnal and tidal variations (periods between 8 and 32 ordinate unit i.e. $6 \mathrm{~h}$ to $32 \mathrm{~h}$ ).

Figure $4 \mathrm{~b}$ display the TVEC variations in TECU $\left(1 \mathrm{TECU}=10^{16}\right.$ electrons $\mathrm{m}^{-2}$ ) over EVPA station and the respective coefficient plot for February 2006. The scale of both axes of coefficient plot is a multiple of $45 \mathrm{~min}$. The diurnal semidiurnal and tidal frequency with varying amplitude is evident.

Next we compare the way the different frequency components of the quantities under study vary by cross-correlating them. As an example Fig. 5 shows the result of the crosscorrelation analysis between Dst and TVEC for the month of December 2005.

The above results indicate that the high frequency components of TEC variation (periods $<3 \mathrm{~h}$ ) do not correlate with Dst variation. Variations of TEC constituent with periods between 4.0 and $7.0 \mathrm{~h}$ are slightly or not correlated with Dst variation while variations with period 8.0 to $10.0 \mathrm{~h}$ are 

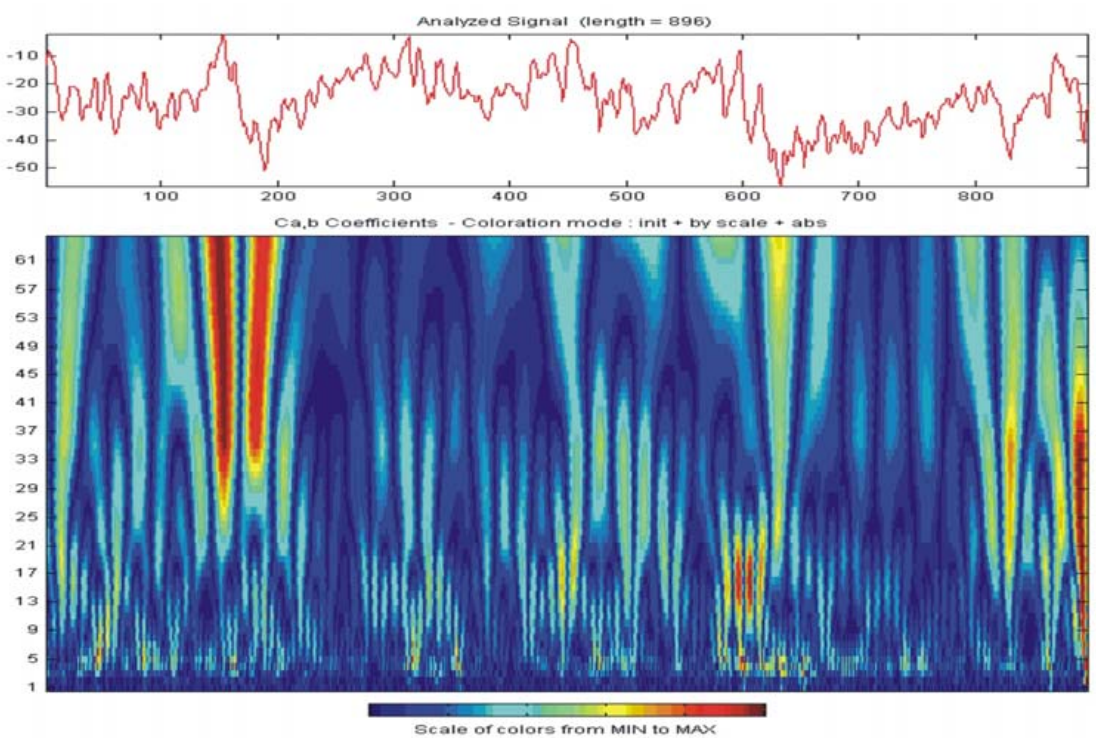

(a)
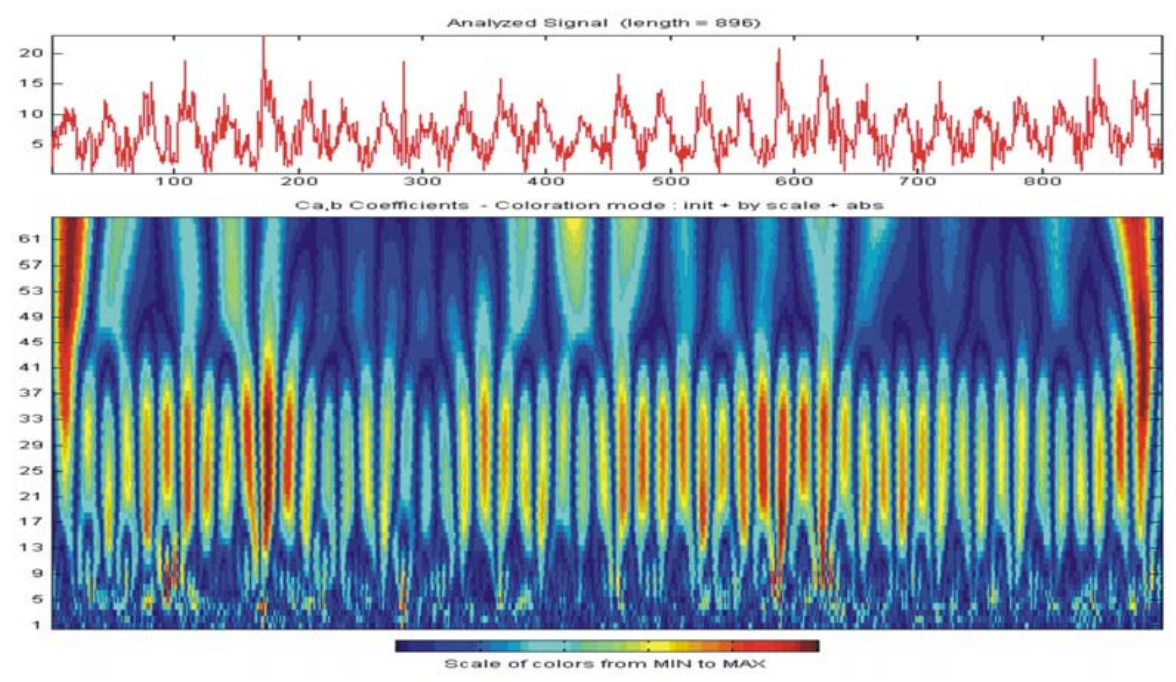

(b)

Fig. 4. (a) Dst variations in $\mathrm{nT}$ and (b) TVEC variations in TECU ( $1 \mathrm{TECU}=10^{16}$ electrons $\mathrm{m}^{-2}$ ) over EVPA station and the respective coefficient plots for February 2006. The scale of both axes of coefficient plots is a multiple of $45 \mathrm{~min}$.

weakly anti-correlated with Dst variations. Finally variations with period higher than $12 \mathrm{~h}$ are weakly correlated and variations with period higher than $24 \mathrm{~h}$ indicate progressively higher anti-correlation with Dst variations, as the period increases. The same results come out by Fourier Transform Analysis.
Figure 6 displays an example of the variation of the correlation coefficient between the TVEC over different sites with frequency. It is evident that the correlation is negligible for remote sites and components with periods smaller than $3.0 \mathrm{~h}$, increases fast with period and is stronger between the TVEC over closely lying sites (EVPA and TRAB in our example). 
Table 4. Events within $20^{\circ}$ distance of selected Lat: $40.45^{\circ}$ Lon: $20.42^{\circ}$, occurred between 1 September 2005 and 1 February 2006 (red cycles in Fig. 2).

\begin{tabular}{|c|c|c|c|c|c|c|}
\hline Date & Ttime & Mag. & Lat. & Lon. & Depth & Description \\
\hline 2006-02-01 & $11: 51: 24$ & 4.5 & 35.2 & 27.7 & 25.0 & Dodecanese Islands Greece \\
\hline 2006-01-16 & 09:18:08 & 4.6 & 34.8 & 45.4 & 50.0 & Iran-Iraq border region \\
\hline 2006-01-08 & $11: 34: 53$ & 6.7 & 36.3 & 23.2 & 60.0 & Southern Greece \\
\hline $2005-12-28$ & 14:08:00 & 4.7 & 38.5 & 39.3 & 5.0 & Turkey \\
\hline $2005-12-27$ & $21: 33: 22$ & 4.8 & 42.4 & 1.5 & 5.0 & Pyrenees \\
\hline $2005-12-24$ & 03:56:07 & 4.6 & 38.8 & 27.8 & 14.0 & Turkey \\
\hline $2005-12-19$ & $17: 44: 47$ & 4.7 & 39.3 & 20.9 & 5.0 & Greece-Albaniaborder region \\
\hline $2005-12-13$ & $12: 14: 44$ & 5.0 & 45.8 & 26.8 & 144.0 & Romania \\
\hline $2005-12-10$ & 00:09:48 & 5.2 & 39.4 & 41.0 & 10.0 & Turkey \\
\hline 2005-12-09 & $14: 33: 20$ & 4.7 & 35.0 & 27.3 & 60.0 & Dodecanese Islands, Greece \\
\hline $2005-12-03$ & $07: 49: 51$ & 4.7 & 45.9 & 27.3 & 30.0 & Romania \\
\hline $2005-11-27$ & $06: 38: 11$ & 4.5 & 33.9 & 26.1 & 60.0 & Eastern Mediterranean Sea \\
\hline $2005-11-26$ & $15: 56: 55$ & 5.2 & 38.2 & 38.9 & 5.0 & Turkey \\
\hline $2005-11-26$ & $04: 51: 17$ & 4.5 & 34.7 & 25.2 & 44.0 & Crete, Greece \\
\hline $2005-11-25$ & 09:30:58 & 5.3 & 35.4 & 23.5 & 40.0 & Crete, Greece \\
\hline $2005-11-24$ & 21:00:19 & 4.5 & 33.9 & 26.1 & 60.0 & Eastern Mediterranean Sea \\
\hline 2005-11-19 & $17: 26: 33$ & 4.5 & 35.2 & 26.1 & 20.0 & Crete, Greece \\
\hline $2005-11-16$ & $16: 40: 35$ & 4.5 & 32.9 & 23.5 & 10.0 & Near coast of Libya \\
\hline $2005-10-31$ & $05: 26: 39$ & 4.9 & 38.2 & 26.8 & 10.0 & Aegean Sea \\
\hline 2005-10-29 & $14: 48: 41$ & 4.5 & 38.1 & 26.6 & 14.0 & Aegean Sea \\
\hline 2005-10-29 & 10:17:07 & 4.6 & 35.5 & 22.4 & 80.0 & Central Mediterranean Sea \\
\hline $2005-10-26$ & $22: 51: 21$ & 4.7 & 45.7 & 26.6 & 142.0 & Romania \\
\hline $2005-10-21$ & $11: 11: 33$ & 4.6 & 37.6 & 20.9 & 25.0 & Ionian Sea \\
\hline $2005-10-21$ & $01: 17: 38$ & 4.8 & 45.5 & 26.5 & 117.0 & Romania \\
\hline $2005-10-20$ & 21:40:01 & 5.7 & 38.2 & 26.6 & 2.0 & Aegean Sea \\
\hline 2005-10-19 & $10: 11: 31$ & 4.6 & 38.1 & 26.7 & 17.0 & Aegean Sea \\
\hline 2005-10-18 & $18: 43: 12$ & 4.5 & 37.5 & 20.9 & 52.0 & Ionian Sea \\
\hline $2005-10-18$ & $15: 36: 31$ & 4.9 & 37.8 & 20.9 & 45.0 & Ionian Sea \\
\hline 2005-10-18 & $15: 26: 01$ & 5.0 & 37.6 & 20.9 & 60.0 & Ionian Sea \\
\hline $2005-10-18$ & $11: 54: 50$ & 4.6 & 40.1 & 20.5 & 30.0 & Greece-Albania border region \\
\hline $2005-10-18$ & $07: 17: 04$ & 4.5 & 38.8 & 39.0 & 5.0 & Turkey \\
\hline $2005-10-17$ & $13: 52: 41$ & 4.5 & 39.7 & 24.6 & 10.0 & Aegean Sea \\
\hline $2005-10-17$ & $09: 55: 31$ & 4.9 & 38.1 & 26.8 & 25.0 & Aegean Sea \\
\hline $2005-10-17$ & $09: 46: 55$ & 5.6 & 38.2 & 26.7 & 10.0 & Aegean Sea \\
\hline 2005-10-17 & $08: 34: 43$ & 4.7 & 38.1 & 26.6 & 15.0 & Aegean Sea \\
\hline 2005-10-17 & $08: 28: 52$ & 4.5 & 38.2 & 26.6 & 14.0 & Aegean Sea \\
\hline $2005-10-17$ & $05: 45: 17$ & 5.0 & 38.1 & 26.7 & 10.0 & Aegean Sea \\
\hline 2005-10-11 & $05: 44: 28$ & 5.0 & 35.4 & 27.6 & 30.0 & Dodecanese Islands Greece \\
\hline $2005-10-06$ & $17: 57: 28$ & 4.5 & 42.7 & 42.1 & 40.0 & Western Caucasus \\
\hline 2005-10-06 & $06: 50: 38$ & 4.6 & 34.2 & 25.9 & 37.0 & Crete Greece \\
\hline $2005-09-27$ & $00: 25: 32$ & 5.1 & 43.2 & 18.2 & 10.0 & North-western Balkan Peninsula. \\
\hline 2005-09-19 & $22: 17: 21$ & 4.8 & 38.3 & 20.3 & 30.0 & Greece \\
\hline $2005-09-16$ & 08:08:51 & 4.7 & 38.3 & 20.1 & 70.0 & Greece \\
\hline $2005-09-13$ & $04: 41: 17$ & 4.5 & 38.4 & 20.3 & 10.0 & Greece \\
\hline 2005-09-11 & $08: 17: 16$ & 4.5 & 37.6 & 21.6 & 59.0 & Southern Greece \\
\hline
\end{tabular}

Table 5. December 2005, Correlation Coefficients between TVEC and Dst.

\begin{tabular}{lcccc}
\hline & GAIA & RABT & EVPA & TRAB \\
\hline Dst & -0.06082 & -0.045424 & -0.03177 & -0.06950 \\
GAIA & & 0.84463 & 0.49357 & 0.53692 \\
RABT & & & 0.42896 & 0.46246 \\
EVPA & & & & 0.90398 \\
\hline
\end{tabular}

2.6 Detection of possible precursory variations in TEC connected with the South-east Aegean and Kythera earthquakes

The comparative analysis of the spectrums of TVEC and Dst variations indicate that the small period TVEC variations (i.e. periods $<3.0 \mathrm{~h}$ ) are not influenced by the variation of the geomagnetic field and in addition the correlation of TVEC over different GPS stations decreases rapidly with period. 


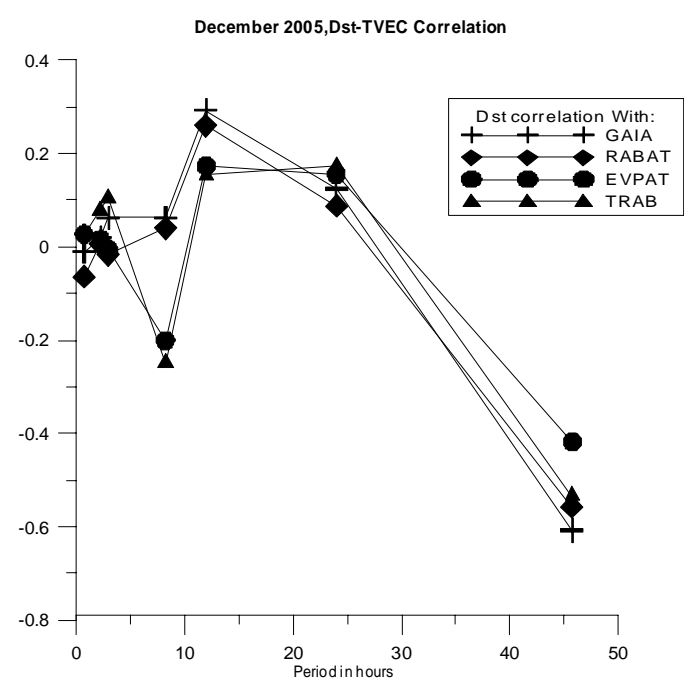

Fig. 5. Variation of Correlation Coefficient Dst-TVEC with frequency (period).

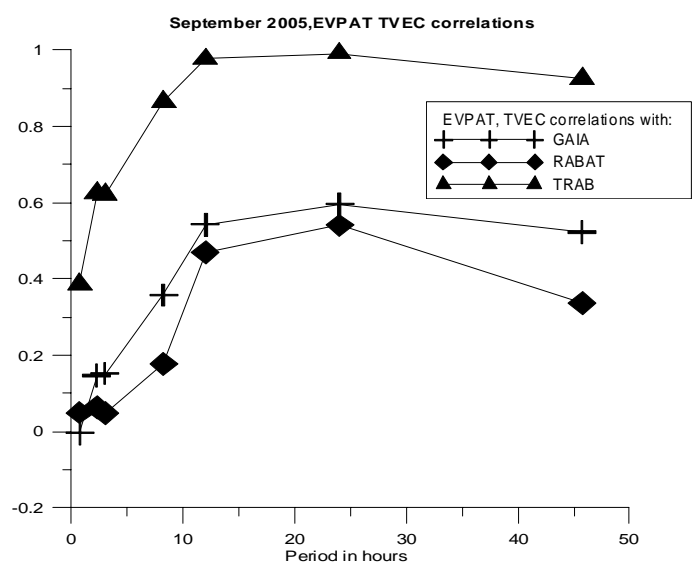

Fig. 6. Variation of the Correlation Coefficient between the TVEC over different sites with frequency.

This means that small period components of TVEC variations are of local nature suitable for the detection of possible earthquake precursors. Thus comparative examination of the spectra of TEC variation over a broad area with due caution on the variation of the geomagnetic field may provide additional arguments for the identification of precursory phenomena. In the case of the seismic activity near the Greek arc which has two distinct maximums (of South east Aegean on 20 of October, see Table 1, and that of Kythera on 8 January 2006, see Table 2) the comparative examination of the Power Spectra of TVEC over the area of Mediterranean indicates that during the month before the main events the components with periods up to the tidal ones increase in number and relative intensity for the TVEC's over the nearest GPS stations i.e. TUC2 and AUT1.
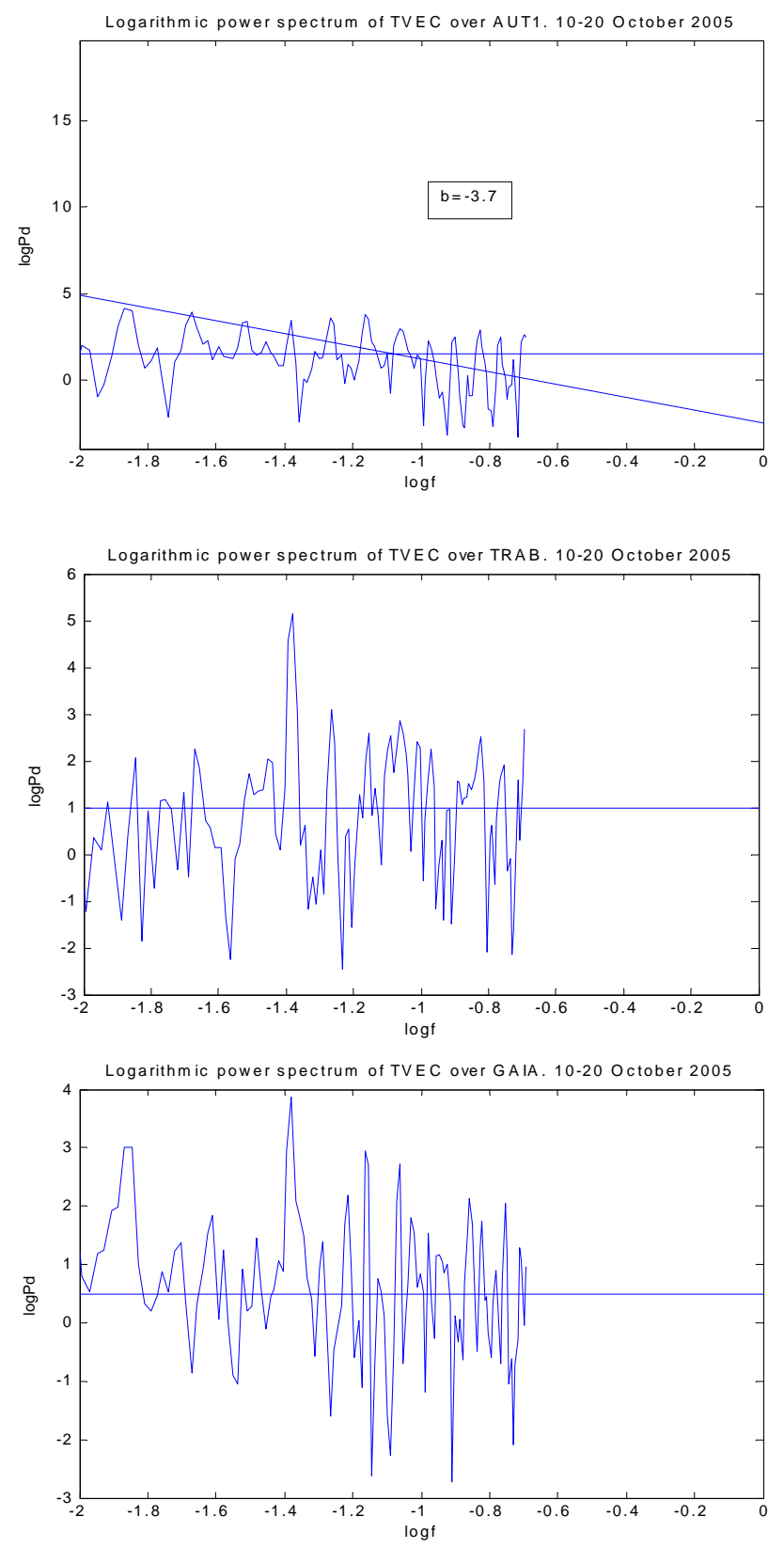

Fig. 7. Logarithmic Power Spectra of TVEC over AUT1, TRAB and GAIA stations in the time period 10-20 October 2005.

As an example Fig. 7 displays the logarithmic power spectra of TVEC over the nearest GPS station i.e. AUT1 for the last 10 days before the event of 20th of October 2005 and Fig. 8 displays the logarithmic power spectra of TVEC over the nearest GPS station, i.e. TUC2 for the last 20 days before the event of 8th of January, 2006. In both cases the logarithmic power spectrum of TVEC over two remote GPS stations, TRAB and GAIA, for the same time period are also displayed. In both cases for the logarithmic power spectrum of TVEC variation over AUT1 and TUC2, the slope for the 

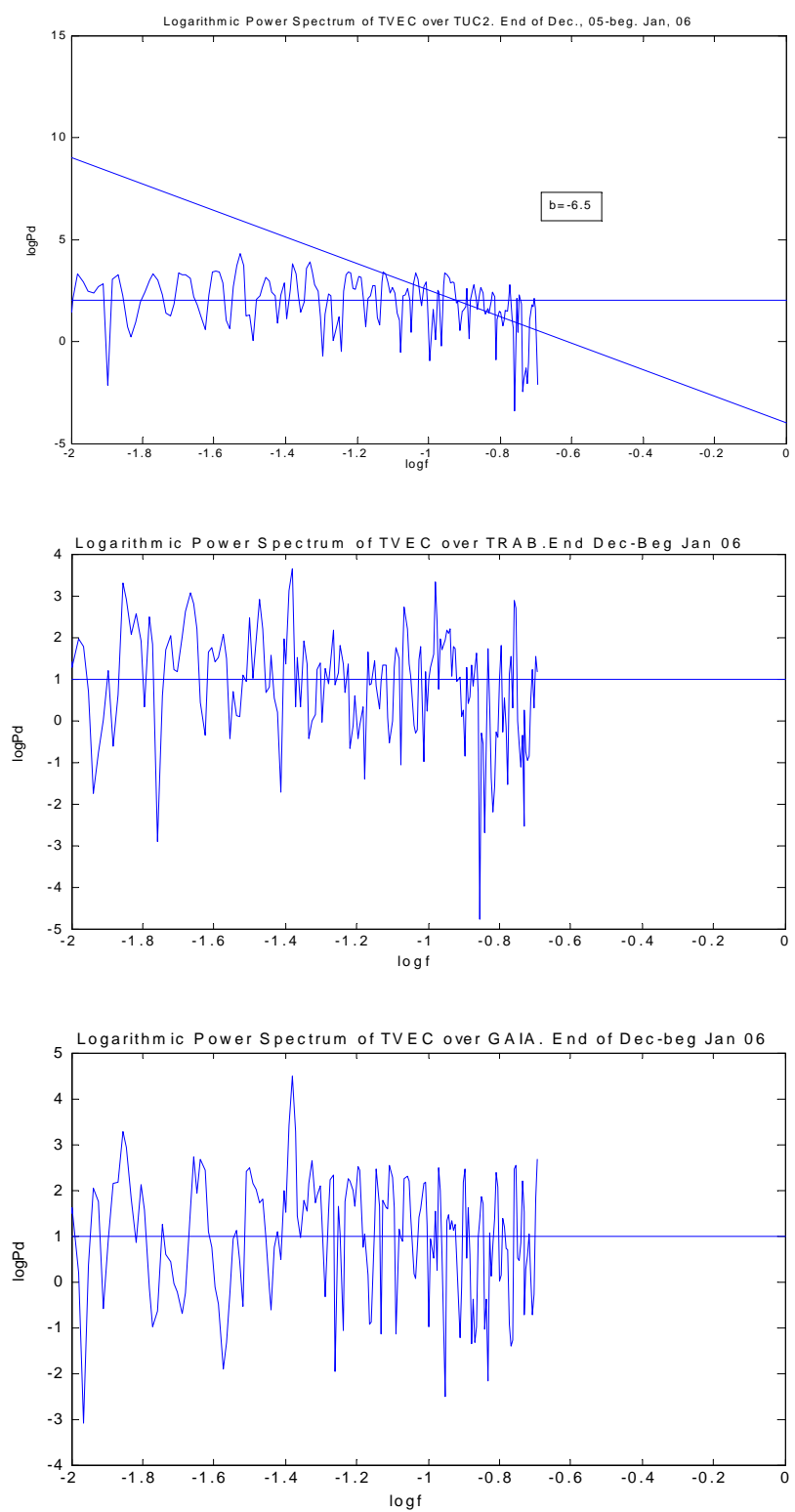

Fig. 8. Logarithmic Power Spectra of TVEC over TUC2, TRAB and GAIA stations in the period 20 December 2005 to 10 January 2006.

high frequency part (periods $<3.0 \mathrm{~h}$ or $\log (f)>-1.1$ for the AUT1 and periods $<2.6 \mathrm{~h}$ or $\log (f)>-0.95)$ is absolutely much higher than -2 instead of being 0 or at most equal to -2 , which stand for a random variation of TVEC (Turcotte, 2007) and is the case depicted in the logarithmic power spectra of the remote stations, TRAB and GAIA, which are flat as it is shown in Figs. 7 and 8. This means that in the logarithmic power spectrum of TVEC over AUT1 and TUC2 not random variations of TVEC with periods ranging between $0.75 \mathrm{~h}$ and $3.0 \mathrm{~h}$ are present.
Characteristics of constituent 1.5hour and signal versus Epicentral distance

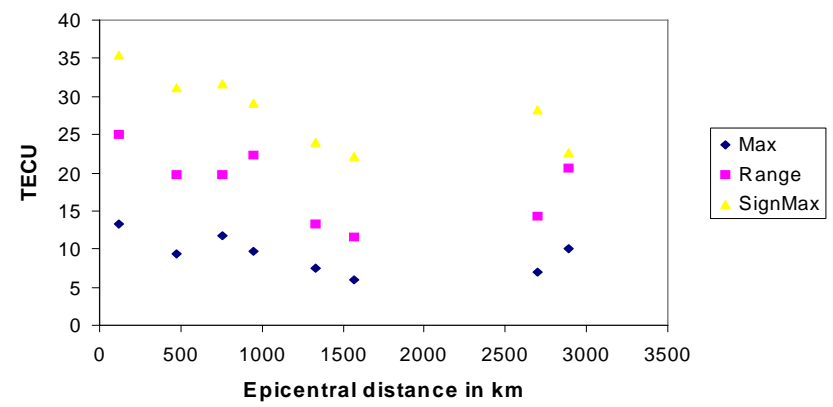

Fig. 9. Signal Maximum, Range and Maximum of 1.5 component versus Epicentral distance.

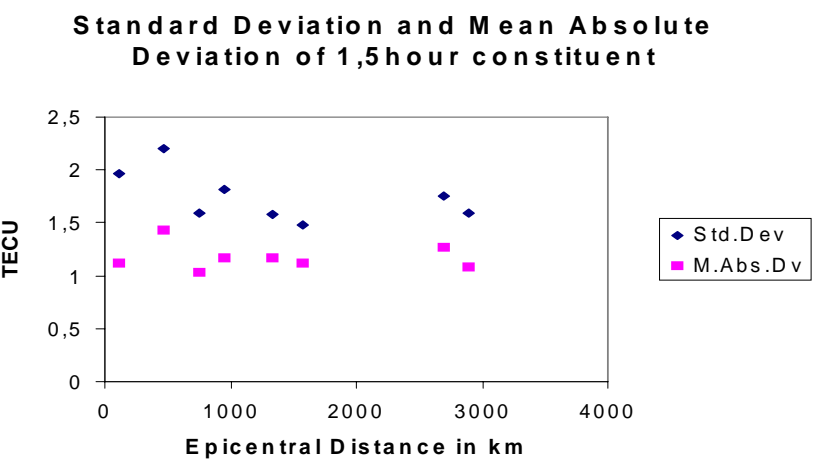

Fig. 10. Standard Deviation and Mean Absolute Deviation of the 1.5 component versus Epicentral distance.

2.7 Identification of the sites which are responsible for the TVEC disturbances

Next in order to get a more accurate determination of the site which is responsible for the TEC disturbance, since all the GPS-stations in the broader area present TVEC exalting, we compare the statistical properties of the $1.5 \mathrm{~h}$ component together with that of the signal for all the GPS stations in order to detect the attenuation effect which indicate the closest to the epicenter GPS station for the strongest event which is the Kythera earthquake of 8 January 2006.

Figures 9 and 10 display the variation of signal Maximum intensity together with the statistics of the $1.5 \mathrm{~h} \mathrm{com-}$ ponent (i.e. maximum value, Range and Standard Deviation) with epicentral distance. The attenuation effect is markedly present in all these quantities. On the base of these results we conclude that the closest GPS-station to the epicenter of the Kythera earthquake of 8 January 2006 is TUC2 as it is shown in Fig. 11.

Figure 12 display the same identification of the closest GPS station for the seismic activity of 20 October 2005, which is AUT1. In this case the maximum in the total signal 
Maximum and Range of 1.5 hour component and Signal Maximum. End of December 2005

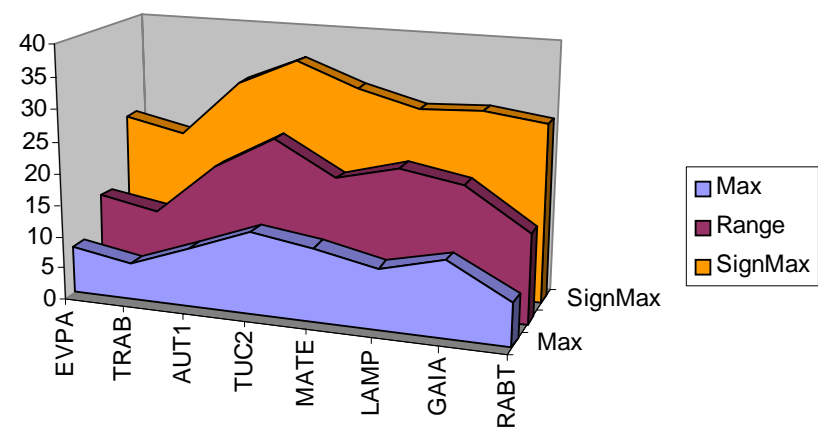

Fig. 11. Identification of the closest to the seismic area GPS station according to the values of the signal and 1.5 component characteristics for the event of 8 January 2006.

Maximum and Range of the 1.5 component and Signal maximum. October 2005

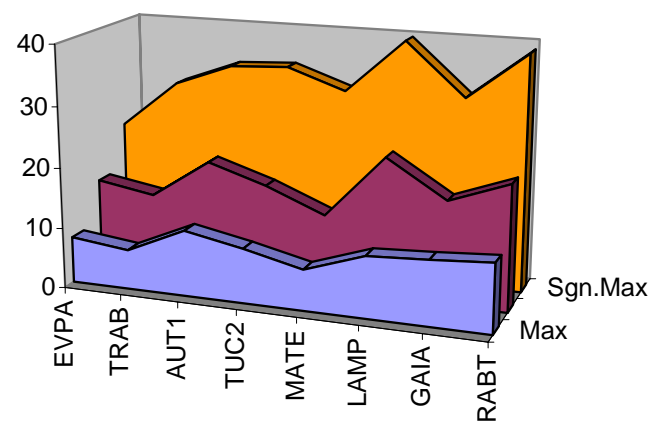

$\square \operatorname{Max}$

$\square$ Range $\square$ Sgn.Max

Fig. 12. Identification of the closest to the seismic area GPS station according to the values of the signal and 1.5 component characteristics, for the event of 20 October 2005.

of the southernmost GPS stations of Rabat and Lampedusa, which present no maximum in the 1.5 component, may reflect the enhancement of TVEC variations due to ionospheric equatorial anomaly. This explanation is in favor of the main result of this analysis that the short-wavelength TVEC variations are more suitable for the detection of local events.

Finally, Figs. 13 and 14 display the variation of TVEC together with the variation of the 1.5 component over TUC2 in the last 20 days before the event of 8 January 2006 and over AUT1 during October 2005 respectively. In these figures the times of the main as well as the pre-shock are shown with arrows. It is apparent that total TVEC as well as the $1.5 \mathrm{~h}$ component sustain exalting in the time interval ranging during the last 14 days before the main shock.
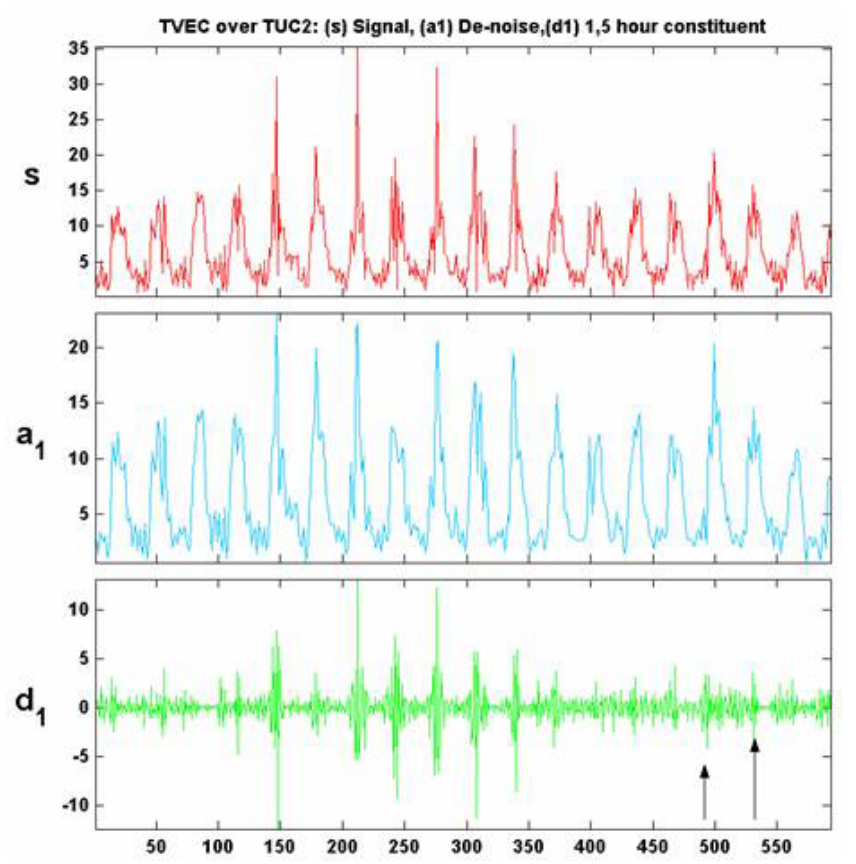

Fig. 13. TVEC and $1.5 \mathrm{~h}$ component variations over TUC2. X-axis in $45 \mathrm{~m}$ multiples, Y-axis in TECU. Arrows indicate the pre-shock (5.0R) and main shock (6.7R) of 8 January 2006.

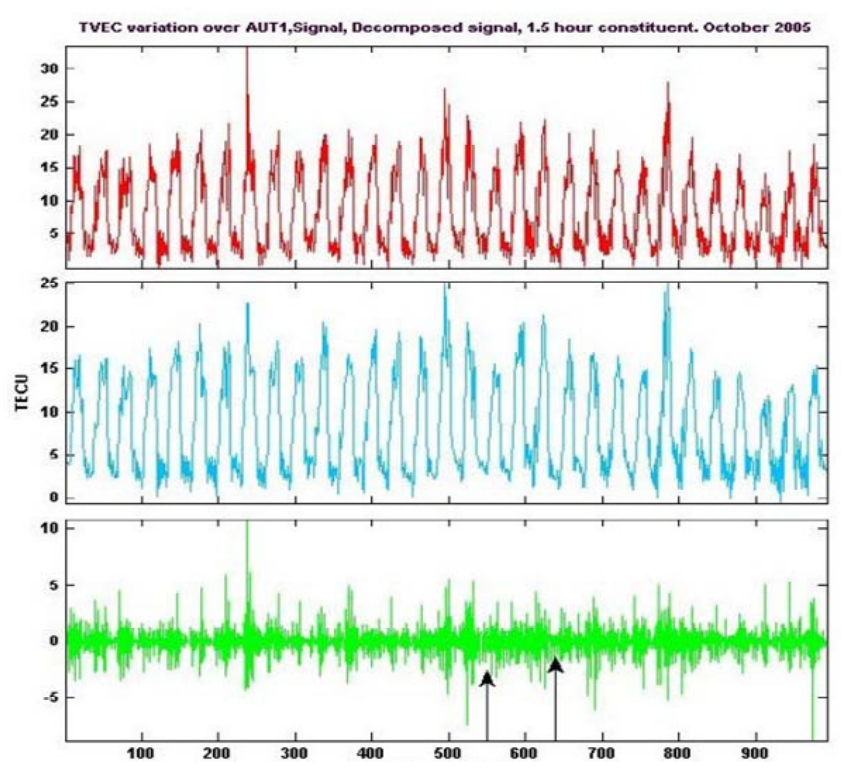

Fig. 14. TVEC and $1.5 \mathrm{~h}$ component variations over AUT1. X-axis in $45 \mathrm{~m}$ multiples, Y-axis in TECU. Arrows indicate the for-shock (5.0R) and main shock (5.6R) of 20 October 2005. 


\section{Conclusions}

In concluding the results of this analysis are the following:

1. The well known daily and seasonal variations of TEC were detected over all sites.

2. The overall variations of Dst do not correlate with TEC variations in different sites. Nevertheless the particular frequency components of TEC correlate or anticorrelate with those of Dst. The TEC components with period less than $4.0 \mathrm{~h}$ are not influenced from the geomagnetic field.

3. The overall variations of TEC over the sites under study are strongly correlated for the sites with close longitudinal location and weekly correlated for sites with remote longitudinal location. This may reflect the earth rotation and tidal influence.

4. The component with period $45 \mathrm{~min}$ is fully uncorrelated for all the remote sites and slightly correlated with closely lying sites. This means that this component is of purely local nature. Because of its small wavelength is strongly attenuated.

5. The components with periods 2 and $3 \mathrm{~h}$ are weakly correlated for the sites with similar longitudinal location and slightly higher for the closest pair of stations (EVPA, TRAB). This may reflect the possible local nature in connection with the smaller attenuation in their pole ward motion.

6. The components with periods ( $8 \mathrm{~h}$ and $12 \mathrm{~h}$ (tidal)), (24 h, (rotational)) and (45 h, Geomagnetic) are strongly correlated for the sites of similar longitude and progressively increased weak correlation for the sites with remote longitude.

7. The constituent of Dst with period $45 \mathrm{~h}$ is anti-correlated with the constituent of TEC with the same period for all the sites. This means that TEC variation of such a period has a geomagnetic causality.

8. It was shown that the TEC intensity and the statistics of the components with small period ( $1.5 \mathrm{~h}$ in our case) present a remarkable attenuation effect.

9. On the base of this result we were able to identify the nearest GPS station to the site of Kythera earthquake, which is TUC2 and to the site of Southeast Aegean, which is AUT1.

10. The $1.5 \mathrm{~h}$ component of TVEC variation over TUC2 and AUT1 sustain exalting within the time period of 14 days before the main shock of Kythera and Southeast Aegean earthquake respectively.
Edited by: P. F. Biagi

Reviewed by: two anonymous referees

\section{References}

Afraimovich, E. L.: The GPS global detection of the ionospheric response to solar flares, Radio Sciences, 35, 1417-1424, 2000.

Afraimovich, E. L., Kosogorov, E. A., Palamarchouk, K. S., Perevalova, N. P., and Plotnikov, A. V.: The use of GPS arrays in detecting the ionospheric response during rocket launching, Earth Planets Space, 52, 1061-1066, 2000.

Afraimovich, E. L., Perevalova, N. P., Plotnikov, A. V., and Uralov, A. M.: The shock acoustic waves generated by the earthquakes, Ann. Geophys., 19, 395-409, 2001, http://www.ann-geophys.net/19/395/2001/.

Afraimovich, E. L., Perevalova, N. P., and Voyeikov, S. V.: Traveling wave packets of total electron content disturbances from global GPS network data, LANL e-print archive, http:// ru.arxiv.org/abs/physics/0211046, http://rp.iszf.irk.ru/homepage/ afra/lastpubl.htm,last access 2008, 2002.

Biagi, P. F., Piccolo, R., Capozzi, V., Ermini, A., Martellucci, S., and Bellecci, C.: Exalting in atmospheric tides as earthquake precursor, Nat. Hazards Earth Syst. Sci., 3, 197-201, 2003, http://www.nat-hazards-earth-syst-sci.net/3/197/2003/.

Calais, E., Minster, J. B., Hofton, M. A., and Heldin, M. A. H.: Ionospheric signature of surface mine blasts from Global Positioning System measurements, Geoph. J. Int., 132, 191-202, 1998.

Calais, E. and Minster, J. B.: GPS detection of ionospheric perturbations following the 17 January 1994, Northridge earthquake, Geophys. Res. Lett., 22, 9, 1045-1048, 1995.

Crowley, G. and Mc Crea: A synoptic study of TIDs observed in the United Kingdom during the first WAGS campaign, 10-18 October 1985, Radio Sciences, 23, 6, 909-917, 1988.

Jacobson, A. R., Carlos, R. C., and Blanc, E.: Observations of ionospheric disturbances following a 5-kt chemical explosion. 1. Persistent oscillation in the lower thermosphere after shock passage, Radio Science, 23, 5, 820-830, 1988.

Konstantinos, K. I., Kalogeras, I. S., Melis, N. S., Kourouzidis, M. C., and Stavrakakis, N.: The South Greece (Kythera) earthquake of 8 January 2006, Seismological Research Letters, 77, 5 September/October, 544-553, 2006.

Koshevaya, S., Makarets, N., Grimalsky, V., Kotsarenko, A., and Perez Enrquez, R.: Spectrum of the seismic-electromagnetic and acoustic waves caused by seismic and volcano activity, Nat. Hazards Earth Syst. Sci., 5, 203-209, 2005, http://www.nat-hazards-earth-syst-sci.net/5/203/2005/.

Liperovsky, V. A., Meister, C.-V., Liperovskaya, E. V., Vasil'eva, N. E., and Alimov, O.: On spread-Es effects in the ionosphere before earthquakes, Nat. Hazards Earth Syst. Sci., 5, 59-62, 2005, http://www.nat-hazards-earth-syst-sci.net/5/59/2005/.

Molchanov, O., Fedorov, E., Schekotov, A., Gordeev, E., Chebrov, V., Surkov, V., Rozhnoi, A., Andreevsky, S., Iudin, D., Yunga, S., Lutikov, A., Hayakawa, M., and Biagi, P. F.: Lithosphereatmosphere-ionosphere coupling as governing mechanism for preseismic short-term events in atmosphere and ionosphere, Nat. Hazards Earth Syst. Sci., 4, 757-767, 2004, http://www.nat-hazards-earth-syst-sci.net/4/757/2004/. 
Molchanov, O., Schekotov, A., Solovieva, M., Fedorov, E., Gladyshev, V., Gordeev, E., Chebrov, V., Saltykov, D., Sinitsin, V. I., Hattori, K., and Hayakawa, M.: Near-seismic effects in ULF fields and seismo-acoustic emission: statistics and explanation, Nat. Hazards Earth Syst. Sci., 5, 1-10, 2005,

http://www.nat-hazards-earth-syst-sci.net/5/1/2005/.

Misiti, M., Misiti, Y., Oppenheim, G., and Poggi, J. M.: Wavelet Toolbox, The Math Works Inc, 1-32 and 6-67, 1996.

Papadopoulos, G. A., Latoussakis, I., Daskalaki, E., Diakogianni, G., Fokaefs, A., Kolligri, M., Liadopoulou, K., Orfanogiannaki, K., and Pirentis, A.: The East Aegean Sea strong earthquake sequence of October-November 2005: lessons learned for earthquake prediction from foreshocks, Nat. Hazards Earth Syst. Sci., 6, 895-901, 2006,

http://www.nat-hazards-earth-syst-sci.net/6/895/2006/.
Rapoport, Y., Grimalsky, V., Hayakawa,M., Ivchenko, V., Juarez, R. D., Kosevaya, S., Gotynyan, O. E.: Change of ionospheric plasma parameters under the influence of electric field which has lithospheric origin and due to radon emanation, Phys. Chem. Earth, 29, 579-587, 2004a.

Rapoport, Yu. G., Gotynyan, O. E., Ivchenko, V. M., Kozak, L. V., and Parrot, M.: Effect of acoustic-gravity wave of the lithospheric origin on the ionospheric $\mathrm{F}$ region before earthquakes, Phys. Chem. Earth, 29, 607-616, 2004b.

Svets, A. V., Hayakawa, M., Molchanov, O. A., and Ando, Y.: A study of ionospheric response to regional seismic activity by VLF radio sounding, Phys. Chem. Earth, 29, 627-637, 2004.

Turcotte, D. L.: Fractal and Chaos in Geology and Geophysics (2nd Ed.), Cambridge University Press, Cambridge, UK, 1997. 